\title{
Treatment of Olive Mill Wastewater and the Use of Polyphenols Obtained After Treatment
}

\author{
Semin OtLes ${ }^{\mathrm{a},}{ }^{*}$ AND IlKNuR SeleK ${ }^{\mathrm{a}}$

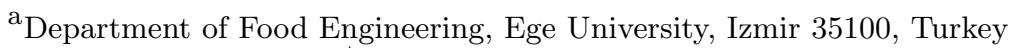 \\ *semih.otles@ege.edu.tr
}

Received: 15 May 2011; Published online: 18 April 2012

\begin{abstract}
Olive mill wastes are significant environmental problem especially in Mediterranean areas where they are generated in huge quantities in a short period of time. They are phytotoxic materials because of their high phenol, lipid and organic acid concentrations, but these wastes also contain valuable resources that could be recycled such as a large proportion of organic matter and a wide range of nutrients. The effluent from olive oil mills contains a large amount of polyphenols that have antioxidant properties. The market value of these antioxidants is high and they are commonly used in the food, cosmetics, pharmaceutics and chemical industries. For the management of olive mill wastewater (OMW) and other olive residues, various treatment methods can be used. Many scientists work on more efficient and cheaper treatment alternatives. Due to the great variety of compounds in the waste, several technologies to remove the harmful compounds for the environment should be used single or together. Some of the most used OMW treatments are drying / evaporation, forced evaporation, thermal treatment, centrifugation-ultrafiltration, electrocoagulation, composting, lagooning, adsorption, powdered activated carbon, filtration, sand filtration, membrane filtration, ultrafiltration, precipitation / flocculation, distillation, electrolysis, co-composting, advanced oxidation processes (AOPs) such as ozonation, hydrogen peroxide / ferrous iron oxidation (the so-called Fentons reagent). Several OMW treatment technologies have been developed aiming at the removal of the main toxic organic compounds. A lot of factors must be considered to choose the treatment methods among them the investment, required area, specific training of the workers, noise and odour emissions and seasonality of production.
\end{abstract}

Keywords: olive mill wastewater; treatment; waste management; polyphenols

\section{Introduction}

The olive oil processing industry has two byproducts whether the press system or threephase centrifugation is used. The first is termed "pomace" or "husk". It is the solids resulting from the squeezed residue. The other is a dark red to black liquid effluent called "olive mill wastewater" (OMW) (Adhoum \& Monser, 2004; Zenjari et al., 2006).

Olive mill wastes represent an important environmental problem especially in Mediterranean areas where they are generated in huge quantities in short periods of time (Hachicha et al., 2009c). Generally, olive mill wastes contain $8396 \%$ water, $3.515 \%$ organics and $0.52 \%$ mineral salts. Sugars (18\%), N-compounds $(0.52 .4 \%)$, organic acids $(0.51 .5 \%)$, fats $(0.021 \%)$, phenols and pectins $(11.5 \%)$ are organic fractions of olive mill wastes (Hanafi, Assobhei, \& Mountadar, 2010). As they have high phenol, lipid and organic acid concentrations, they are phytotoxic materials and cause serious environmental concerns that are also related to treatment costs. However, these wastes also contain valuable resources such as a large proportion of organic matter and a wide range of 
Olive Mill Wastewater Treatment and Polyphenols $\mid 86$

nutrients that could be recycled (Hachicha et al., 2009c; Azbar et al., 2004).

The amount of OMW and its composition depends on the type of production process. For example, one type of production process, traditional presses, produces about $400 \mathrm{~L}$ of liquid waste per tonne of processed olives, while the new three-phase decanting method produces about $750 \mathrm{~L}$ per tonne of processed olives. The same is true for all olive mill effluents (OME). The traditional cold press method generates about $50 \%$ of OME, while the continuous centrifugation process generates $80-110 \%$ of OME due to the continuous washing of olive paste with warm water prior to oil separation. Typically, this wastewater is characterized by an intensive dark brown to black colour, strong acidic smell unique to olives, very high biological oxygen demand (BOD) values $\left(1260 \mathrm{~g} \mathrm{~L}^{-1}\right)$, chemical oxygen demand (COD) values (in the range of $\left.80200 \mathrm{~g} \mathrm{~L}^{-1}\right)$, total solids content $\left(40150 \mathrm{~g} \mathrm{~L}^{-1}\right)$ and acidic $\mathrm{pH}$ (about 5). The high concentration of polyphenols, up to $10 \mathrm{~g} \mathrm{~L}^{-1}$ depending on the type and origin of the effluent, which are toxic to bacteria commonly used in biological oxidation plants, is an important negative property of OMW. One of the other major problems is caused by the seasonality of the production that typically lasts between December and February (Panizza \& Cerisola, 2006; Mantzavinos \& Kalogerakis, 2005).

A growing interest in the development of innovative treatment methods for this type of wastewater has emerged in the last few years. Furthermore, environmental regulations and enforcement have become more stringent (Panizza \& Cerisola, 2006). Guidelines to manage these wastes through technologies that minimise their environmental impact and lead to a sustainable use of resources is needed. Thus, the management of OMW has been extensively investigated and some extensive and detailed reviews about its management have been published recently. According to literature reviews, the currently employed systems for OMW treatment can be classified as biological, physicochemical or combined processes. Among these processes, advanced oxidation processes (AOPs) like electrochemical oxidation have been increasing recently (Lafi, Shannak, Al-Shannag, Al-Anber, \&
Al-Hasan, 2009). This article provides a summary of updated information on research that propose different valorisation methods based on traditional and decanter systems for olive mill waste. Additionally, polyphenols in olive mill waste water and their intended use are referred to.

\section{Proposed valorisation methods of olive mill wastewaters}

In recent years many management options have been proposed for the treatment and valorisation of OMW. Most of these methods aim to reduce the phytotoxicity in order to reuse it for agricultural purposes. However, few techniques have been applied on an industrial scale because of the high cost of the treatment plant. More recently other alternative methods have also been proposed (Zenjari et al., 2006; Roig, Cayuela, \& Sanchez-Monedero, 2006).

\subsection{Direct application on soil}

Many researchers have applied OMW directly on soil with the aim of testing its effects as an organic fertiliser and have found positive and negative effects. Negative effects are associated with its high mineral salt content, low $\mathrm{pH}$ and the presence of phytotoxic compounds, especially polyphenols. Positive effects are related to its high nutrient concentration, especially $\mathrm{K}$, and its potential for mobilizing soil ions (Roig et al., 2006). The practice of spreading OMW directly on agricultural soils may result in more damage than beneficial effects. OMW has a dark colour because of polymerisation of tannins and low molecular weight phenolic compounds. Thus, some technologies must be applied to OMW to remove the phenolic fraction, before use for irrigation purposes (Adhoum \& Monser, 2004). In one study, OMW without pre-treatment was applied on a wheat crop for 3 years and some necrotic spots on the leaves and a reduction in secondary stems emergence were observed. However, at harvest no significant differences were observed in grain yield. OMW might reduce the mobility of certain organic compounds in soil. It is suggested that it is used to attenuate leaching 
of toxic organic chemicals such as herbicides in cultivated lands. Another characteristic of OMW is its high antimicrobial capacity, which can be used for soil sanitation against certain pathogens: OMW suppresses the plant pathogen Rhizoctonia solani. Therefore, its addition prior to planting could be a good preventative measure (Roig et al., 2006).

\subsection{Physical treatment}

Dilution, incineration, evaporation, sedimentation, filtration and centrifugation are some of simple physical processes that can be used. None of these processes alone is able to reduce the organic load and toxicity of OMW to acceptable limits (Hanafi et al., 2010). Physical methods involve high energy costs and the emission of air pollutants, and although ultrafiltration/reverse osmosis are/is quite simple to carry out efficiently, they have the drawback of producing a concentrate sludge solution to be disposed of and are complicated by rapid membrane fouling caused by the high organic content of the OMW (Panizza \& Cerisola, 2006). The most frequently used physical treatments are mentioned below.

\section{Evaporation}

In practical terms, the most common treatment method is through evaporation in storage ponds in the open because of the low investment required and the favourable climatic conditions in Mediterranean countries. The large area needed, bad odour, infiltration and insect proliferation are negative properties of evaporation (Roig et al., 2006).

According to some studies, a cost-effective practice of OMW treatment is its storage in evaporation ponds. In the hot period of the year, the effluent is collected and stored in ponds where it undergoes natural evaporation until becoming completely dry. As a consequence, the polyphenolic compounds are concentrated and the polluting effluent is transformed into solid hazardous waste. Since it has a high organic load and contains the substantial amounts of plant nutrients (N, P, K, Ca, Mg and Fe) in OMW sludge, composting such sludge for the production of or- ganic fertilizer seems to be an appropriate solution (Hachicha et al., 2009b)

Another alternative OMW treatment is vacuum evaporation producing distillate and concentrate. Distillate is produced continuously, and a discontinuous concentrate automatically discharged. Sodium hydroxide was used to neutralize wastewater during distillation in a study that was carried out by Azbar et al. (2004). As a result, the distilled water volume reached $90 \%$ of the wastewater input. Although the distillate is a colourless liquid, its COD is 3000-4000 $\mathrm{mg} \mathrm{L}^{-1}$ showing that further treatment is still required. Biological oxidation of the distillate preceded by $\mathrm{pH}$ adjustment and $\mathrm{C}: \mathrm{N}: \mathrm{P}$ correction gave a treated water complying with the wastewater discharge regulations. The concentrate and the olive mill solid residues can be mixed. This mixture can either be de-oiled and burned or used for various purposes such as animal fodder or fertilizer, as it contains $14 \%$ protein and $5 \%$ potassium (Azbar et al., 2004).

\section{Evaporation-Hydrolysis-Oxidation (EHO)}

Here, following a preconcentrating step by evaporation, hydrolysis and subsequent oxidation take place under controlled heat input by air. The EHO process is carried out in several steps: the removal of the sludge for utilization in pulp oil manufacturing and fuel production, removal of residual fatty acids as much as possible by means of a ceramic ultrafiltration membrane, removal of substances with phytotoxic effects from the wastewater, recovery of materials that could be used for the production of industrial oils or as fuel and collection and transportation of olive oil wastewaters, and further treatment of the water obtained if necessary (Azbar et al., 2004).

\section{Centrifugation-Ultrafiltration}

This combined process provides both the reduction of pollution caused by the wastes and the selective separation of some useful products that are present (fats, sugars, polyphenols, etc.). The treatment consists of a preliminary centrifugation step, in which the suspended solids are removed, followed by an actual selective separa- 
Olive Mill Wastewater Treatment and Polyphenols $\mid 88$

tion phase, carried out by ultrafiltration (UF) of the centrifuge supernatant. Approximately $90 \%$ COD reduction is achieved with the combination of centrifugation and ultrafiltration. Additionally, a complete separation of fats that are rejected by the membrane, from salts, sugars and polyphenols, contained in the permeate, is attained (Adhoum \& Monser, 2004; Turano, Curcio, De Paola, Calabro, \& Iorio, 2002).

\subsection{Physico-chemical treatments}

Physico-chemical processes such coagulation, flocculation, oxidation processes have also been employed in OMW treatment. They are both simple and cheap. Additional chemicals are used in these processes in order to destabilize the suspended and colloidal matter of OMW and form an insoluble solid that can be removed easily from the waste. Oil, suspended solids, COD, and BOD are decreased in this way. Destabilization of these colloids can be achieved either by reducing or increasing $\mathrm{pH}$ (neutralization) or by the addition of a precipitate-inducing agent (precipitation/flocculation). One of the major disadvantages is that they are only a partial solution and must be followed by a secondary treatment to comply with legal requirements because the treated liquid still has a high polluting load. Thus, they are more suitable as pre-treatment methods. The other one is the large quantities of sludge that cause other environmental problems (Panizza \& Cerisola, 2006; Tsagaraki, Lazarides, \& Petrotos, 2007).

The most important inorganic flocculants that have been used for OMW treatment are ferric and ferrous chloride, ferric sulphate, and aluminium sulphate. In addition, aluminum chloride, calcium hydroxide, and their combinations added as different anionic polyelectrolytes, also sulphuric acid, were tested by several researchers. None of these reagents should be used if the precipitated material is to be used as animal feed (Azbar et al., 2004; Tsagaraki et al., 2007). In one study, calcium hydroxide and aluminium sulphate were used to reduce COD to $2030 \%$ of initial values (Roig et al., 2006).

In another study (Aktas, Imre, \& Ersoy, 2001), effects of lime treatment on the waste samples were investigated. In conclusion, it was indicated that the lime pre-treatment proposed to reduce the polluting effect of OMW is an applicable method in practice since lime can easily be purchased anywhere and it is cheaper than other chemicals such as aluminium sulphate, ferric chloride, magnesium sulphate, etc., used for pretreatment of wastewaters. Also, a large proportion of the pollutant substances in OMW can be removed with the process described in this study. Chromatographic studies on lime treated phenolic substances showed that o-diphenols which are highly phytotoxic could be removed totally by lime. With lime treatment, a large proportion of the fatty components, which prevent the evaporation of water by forming an impermeable film on the surface of the wastewater in the ponds, can be removed. Therefore, after lime treatment the liquid phase is evaporated more easily than the raw wastewater which is in the ponds. After lime treatment, OMW can be filtered more easily through a cotton cloth by using a mechanical press due to removing the colloidal compounds by lime treatment (Aktas et al., 2001). Several companies have developed a new technology that consists of the flocculation of the organic matter of OMW with a commercial organic polyelectrolyte. This process allows the water that is produced to be used for irrigation and the solid fraction of OMW can be successfully composted with other agricultural by-products (Roig et al., 2006).

\subsection{Electrocoagulation}

Electrocoagulation (EC) is an electrochemical method that was developed to overcome the drawbacks of conventional water and wastewater treatment technologies. In this method, the coagulant is generated in situ by electrolytic oxidation of an appropriate anode material that, at appropriate $\mathrm{pH}$, leads to the formation of insoluble metal hydroxide that is able to remove pollutants by surface complexation or electrostatic attraction. The basic advantages of this technique are its simple equipment, easy management and automation and a decreased amount of sludge. It was shown to be an effective and reliable technology that provides an environmentally compat- 
ible method for reducing a large variety of pollutants. Also, EC avoids the need for treatment of the OMW with any chemical reagents, and the consumption of electric power is low enough. Lastly, the input of metal (aluminium) is very small. Electrocoagulation has successfully been used for the treatment of wastewaters including dairy wastewater, alcohol distillery wastewater, textile wastewaters, leachate, restaurant wastewater, oil refinery wastewater, chemical mechanical polishing wastewater and also the defluoridation of drinking water (Hanafi et al., 2010; Adhoum \& Monser, 2004; Inan, Dimoglo, Simsek, \& Karpuzcu, 2004).

Electrocoagulation can remove more than $70 \%$ of COD, polyphenols and the dark colour present in olive mill wastewater due to the in situ electrogeneration of aluminium hydroxide, electrochemical oxidation and reaction with soluble aluminium species (Hanafi et al., 2010). Optimum removal was obtained after 15 min of treatment by the addition of $2 \mathrm{~g} \mathrm{~L}^{-1} \mathrm{NaCl}$ to the wastewater and by applying $250 \mathrm{~A} \mathrm{~m}^{-2}$ as current density. The naturally occurring $\mathrm{pH}$ of OMW is appropriate to achieve effective treatment. The final $\mathrm{pH}$ of treated OMW is nearly neutral which allows it to be directly treated by biological methods. Adhoum and Monser (2004) also worked on EC using aluminium electrodes to investigate the treatment of OMW. The removal efficiency of the treatment was determined by monitoring the decrease of total phenol, COD and dark colour intensity. They concluded that electrocoagulation treatment achieves a fast and effective reduction of pollutants $(\approx 76 \%$ of COD, $\approx 91 \%$ of polyphenol and $\approx 95 \%$ of dark colour) present in fresh and stored OMW. In addition, it was demonstrated that the naturally occurring $\mathrm{pH}$ of OMW is appropriate to achieve an effective treatment. Moreover, the final $\mathrm{pH}$ of treated OMW was nearly neutral which allows it to be directly discharged in natural aquatic streams (Adhoum \& Monser, 2004).

\subsection{Composting}

Composting is one of the main technologies for recycling OMW and transforming it into a fertiliser (Roig et al., 2006). It is an efficient method of waste disposal, enabling recycling of organic matter (Hachicha, Hachicha, Trabelsi, Woodward, \& Mechichi, 2009a). Composting can be described as a process where the activity of endogenous microorganisms is enhanced by the physico-chemical environmental parameters of the composted solid matrix (Hachicha et al., 2009b).

This process allows the return of nutrients to cropland. In addition, composting avoids the negative effects often observed when these wastes are directly applied to soil (Roig et al., 2006). Solid olive and olive tree waste, barley straw, wheat straw, maize straw, poplar sawdust with bark chips and cotton waste are some of bulking agents have been used in compost with OMW. Generally, a few weeks are enough to remove phytotoxicity (Hachicha et al., 2009c; McNamara, Anastasiou, O'Flaherty, \& Mitchell, 2008; Zenjari et al., 2006). Recently, poultry manure was used as a major co-substrate during composting. With all agents, a high degree of humification, no phytotoxic effect and improved mineral nutrients content are observed in the final product (Hachicha et al., 2009c).

OMW composts were applied to cultivate horticultural and other crops. Yields obtained with compost fertilisation were similar to, and sometimes higher than, those obtained with mineral fertilisers (Roig et al., 2006). Co-composting OMW sludge with other organic residues to provide adequate chemical composition could be a suitable treatment, reducing the phytotoxic effects of the phenolic and lipid compounds present in the sludge. The resulting compost is a suitable soil improver, providing beneficial effects in terms of soil properties, particularly in reducing the soil organic matter deficit in arid regions. Various publications report reductions in phenolic and fat content following the composting process (Hachicha et al., 2009a).

The changes occurring in organic matter, phenols and biotoxicity on composting OMW with barley straw was studied to test the feasibility of including it in a composting process and to evaluate the efficiency of the treatment in degrading the phenolic components, thereby reducing the toxicity of the effluent (Zenjari et al., 2006). The OMW was mixed with a cellulose-rich waste product and the resulting damp organic 
Olive Mill Wastewater Treatment and Polyphenols $\mid 90$

matter composted. As a result, the total organic matter decreased, with a drop of $25 \%$ being reached after the stabilization phase and $52 \%$ at the end of the maturation phase. Degradation of the phenols reached $54 \%$ and $95 \%$, respectively, after these periods. The toxicity of the water extract, evaluated by Photobacterium phosphoreum fluorescence, disappeared after only two months of composting. This trend was confirmed by the tight correlation between the physicochemical and toxicity parameters, indicating that the degradation of organic matter leads to a strong reduction of the $\mathrm{C} / \mathrm{N}$ ratio and of toxicity. The results obtained indicate a normal process of humification occurring during the composting of the formerly highly toxic OMWstraw mixture, resulting in a product, which has good agricultural properties as organic fertilizer.

Hachicha et al. (2009c) examined the changes that occur in the content of phenolic compounds and the biotoxicity of the oxidized substrate which results from the composting of OMW sludge with sesame bark. They concluded that the total organic matter decreased by $52.72 \%$ while water-soluble phenol degradation decreased by $72 \%$ after 7 months of processing. They used gas chromatography coupled with mass spectroscopy to confirm the elimination of polyphenols during composting. Initially, the analysis showed three abundant polyphenolic compounds, one of which was identified as the 4-hydroxyphenyl-ethanol (tyrosol), a wellknown antioxidant in OMW. After 7 months of composting, all of the phenolic compounds had disappeared. The phytotoxic effects of OMW sludge, assessed by the plant index germination, increased during the composting to reach $80 \%$ after 210 days. This trend was confirmed by the correlation between physico-chemical and toxicity parameters. They concluded that the results obtained confirmed the stability of the compost prepared from OMW sludge with sesame bark and indicated a gradual detoxification as the compost matured.

\subsection{Biological treatments}

Biological treatments are also generally used for the treatment of OMW. The advantages can be arranged in this order:

- some materials that are difficult to treat by ultrafiltration, such as fatty acids, can be biologically treated.

- some materials, such as amines, can be biologically treated, whereas they cannot be treated by either chemical or ultrafiltration methods.

However they also have some disadvantages:

- some chemical compounds do not readily degrade by biological treatment.

- Biocides used in the manufacturing environment greatly inhibit biological reactions.

- Digestion rates are slow, in general taking days or weeks, requiring large storage tanks.

- Bacteria must be fed constantly, or they will die off. If they die off, re-acclimatising the bacteria to the waste stream may take several days (Lafi et al., 2009).

\section{Aerobic treatments}

Another way to manage OMW is by aerobic treatment with micro-organisms, which has also been used to remove the pollution effect of OMW (Anastasiou, Christou, Michael, Nicolaides, \& Lambrou, 2011). Aerobic bacteria have been tested primarily to remove phytotoxic compounds (i.e., monoaromatic or simple phenolics) from OMW, although some studies have also focused on reduction of COD. The bacteria appear to have a minimal effect on more complex polyphenolics responsible for the dark coloration of OMW. Furthermore, they appear to be very effective against some phenolic compounds and relatively ineffective against others. For example, Bacillus pumilus was able to completely degrade protocatechuic acid and caffeic acid but had much less effect on tyrosol. On the other hand, Arthrobacter transformed tyrosol to 4hydroxyphenyl acetic acid.

Studies related to the aerobic treatment of OMW are generally focused on the degradation of the main responsible compounds for phytotoxicity, phenolic compounds. Many 
microorganisms have been tested: Bacillus pumilus, Arthrobacter, Azotobacter vinelandii, Pseudomonas putida and Ralstonia sp. and various bacterial consortia (Anastasiou et al., 2011; Roig et al., 2006). Most aerobic biological processes, technologies and microorganisms have been tested for the treatment of OMWs, aimed at reducing organic load, dark colour and toxicity of the effluents. In general, aerobic bacteria appeared to be very effective against some low-molecular-mass phenolic compounds but are relatively ineffective against the more complex polyphenolics responsible for the dark colouration of OMWs (Morillo, Antizar-Ladislao, Monteoliva-Sanchez, RamosCormenzana, \& Russell, 2009).

An aerobic pre-treatment stage can be applied for reducing the amount of total phenolic compounds and associated toxicity to enhance the anaerobic digestion of OMW. Thus, the combination of aerobic and anaerobic treatment has been extensively studied, as there are aerobic consortia that grow on undiluted or diluted OMW and are capable of metabolizing and removing its aromatic compounds (Tsagaraki et al., 2007). The effect of aerobic pre-treatment using three different cultures (Aspergillus terreus, Azotobacter chrococcum, Geotrichum candidum) on the subsequent anaerobic digestion of OMW has been studied and it has been found that the rate of anaerobic degradation is about 2.5-4.5 times greater (depending on the culture used) than that of the anaerobic degradation without pre-treatment (Mantzavinos \& Kalogerakis, 2005). This was attributed to the fact that pre-treatment is capable of reducing the COD and total phenol concentration as well as toxicity by about $63-75 \%, 65-95 \%$ and $59-87 \%$, respectively, for the various cultures used. In further studies, it was found that pre-treatment of a thermally processed OMW with Pleurotus ostreatus is capable of enhancing the performance of subsequent anaerobic digestion. Aerobic treatment for 21 days led to about $65 \%$ phenols removal, which is enough to remove inhibition against methanogenic bacteria. Several other studies have dealt with the efficiency of aerobic degradation concerning phenols and toxicity removal and representative literature. According to studies, various strains of Pleurotus were an- swer for $69-76 \%$ removal of phenols after $12-15$ days in shake flasks. Phototoxicity was reduced following treatment but not proportionately to phenols removal. Pleurotus ostreatus achieved nearly complete removal of phenols after 20 days in batch fermenter. Phototoxicity and toxicity to marine and soil bacteria were reduced following treatment. Phanerochaete flavido-alba procured $70 \%$ color and $52 \%$ aromatic compounds removal from OMW after 14 days in batch fermenter. Lentinula edodes procured $40 \%$ total phenols, $60 \%$ o-diphenols and $50 \%$ color removal with immobilized cultures in fixed bed reactor with recirculation. Phytotoxicity eliminated with treatment with Azotobacter vinelandii for 5 days in rotating biowheel fermenter. In studies that used various strains of Penicillium, 32-45\% removal of phenols and 25-38\% COD removal after 20 days in flasks were observed. In another study, it was concluded that Lentinula edodes achieved $84 \%$ total phenols, $90 \%$ o-diphenols, $73 \%$ TOC and $75 \%$ color removal after 8 days with immobilized cultures in shake flasks. With used Phanerochaete chrysosporium, Aspergillus niger, Aspergillus terreus, Geotrichum candidum cultures, $92 \%$ phenols, $100 \%$ o-diphenols and $75 \%$ COD removal after 6 days with $P$. chrysosporium in batch fermenter achieved. Respective values were $76 \%, 82 \%$ and $73 \%$ after 4,8 days with $A$. niger and $64 \%, 76 \%$ and $63 \%$ after 4,7 days with $A$. terreus were observed. In addition, no phenols and only $10 \%$ o-diphenols removal after 9,3 days with $G$. Candidum were observed. Coriolus versicolor and Funalia trogii cultures was answer for $93 \%$ phenols, $81 \%$ color and $70 \%$ COD removal after 6 days with $F$. trogii in shake flasks. Respective values were $90 \%$, $65 \%$ and $63 \%$ with C. Versicolor (Mantzavinos \& Kalogerakis, 2005). In a study on fermentation of OMW by Coriolus versicolor, Funalina trogii, Phanerochaete chrysosporium ME446, Pleurotus ostreatus, Pleurotus sajor-caju, Lentinus tigrinus and Laetiporus sulphureus (brown-knot fungus) Yesilada, Sik, and Sam (1999) found that C. versicolor, F. trogii and P. sajor-caju showed higher removal potential than the other fungi. In this study, carbon, energy and other nutrient sources were not added to the OMW. In addition to this, high laccase enzyme activity was determined in OMW culture media with these fungi. It was 
Olive Mill Wastewater Treatment and Polyphenols $\mid 92$

found that white-rot fungi could remove up to $93 \%$ of the phenols present in OMW. Researchers reported that white-rot fungi removed phenols and induced a remarkable decrease in toxicity.

\section{Anaerobic treatments}

The production of energy (biogas) and the potential re-use of the effluent in irrigation are the main reasons to use anaerobic digestion for OMW treatment. The major limitation of this treatment is the inhibition of methanogenic bacteria by the phenolic compounds and the organic acids present in the OMW. Anaerobic filters or up-flow anaerobic sludge bed reactors are suitable for treating OMW but a pre-treatment stage is necessary to remove undesirable compounds. It was proposed that sedimentationfiltration pretreatment prior to anaerobic digestion is a useful way of OMW disposal (Roig et al., 2006).

Bacteria are mostly used for anaerobic processes and they have three major steps:

1. Anaerobic bacteria hydrolyze complex organic compounds, such as polysaccharides and polyphenols to their monomers (simple sugars and phenols, respectively).

2. These molecules are converted into organic acids such as acetic, lactic and formic acids and alcohol by acetogenic bacteria during the second stage of the process.

3. In the last stage, methanogenic bacteria, which are characterized by their sensitivity to $\mathrm{pH}$ and temperature changes, convert the organic acids into biogas (a mixture of $6080 \%$ methane and other gases, mainly carbon dioxide).

The factors that affect the anaerobic processes are temperature, retention time, $\mathrm{pH}, \mathrm{H}_{2}$ partial pressure, the chemical composition of the wastewater and the quantity of toxic substances present. The process usually takes place under thermophilic or mesophilic conditions. Retention time varies between 10 and 35 days and $\mathrm{pH}$ must be controlled because acetogenic bacteria tend to lower it and methanogenic bacteria are sensitive to $\mathrm{pH}$ variations (Tsagaraki et al., 2007).

A significant advantage of anaerobic processes over aerobic may be the generation of methane, which could potentially be used in remediation or as an energy source for other processes (McNamara et al., 2008). The other advantages of this treatment are:

- quite a high degree of purification with highorganic-load feeds can be achieved;

- low nutrient requirements are necessary;

- small quantities of excess sludge are usually produced.

However, its high $\mathrm{C} / \mathrm{N}$ ratios $(\approx 50)$, low $\mathrm{pH}$ $(\approx 5)$, low alkalinity $\left(\approx 0.6\right.$ g $\mathrm{CaCO}_{3}$ per litre $)$ and the presence of biostatic and inhibitory substances constitute a nutrient imbalance and present a problem for the anaerobic degradation of wastewaters. To overcome this problem, wastewaters can be subjected to pre-treatments before anaerobic digestion. The pre-treatment choices are dilution with water, aerobic biological treatment, pre-treatment with specific aerobic organisms like the fungi Phanerochaete chrysosporium and the addition of a source of nitrogen. Another approach adopted by researchers is the co-digestion of OMW with other substrates to compensate for its low alkalinity and nitrogen. For example, co-digestion with nitrogen-rich substrates such as animal manure and olive mill solid waste has been explored (Morillo et al., 2009; Roig et al., 2006).

\section{Integrated Biological Processes}

Single anaerobic or aerobic processes do not fully match treatment requirements even when achieving the maximum removal efficiencies. Therefore, combined systems have also been studied. The biological process for OMW treatment is based on methanization step and aerobic posttreatment followed by an aerobic detoxification step. In one study, the first aerobic detoxification step of OMW supplemented with sulphate and ammonium was carried out by the growth of Aspergillus niger in a bubble column (Hamdi, Garcia, \& Ellouz, 1992). Researchers demonstrated that this first step decreased OMW toxicity and increased its biodegradability by phenolic compounds degradation. Growth of A. niger resulted in biomass containing $30 \%$ proteins $(\mathrm{w} / \mathrm{w})$ and 58\% COD removal. Filtration 
of OMW was enhanced by this fermentation because the suspended solids were trapped in the mycelium. The filtrate liquid was then methanized using an anaerobic filter packed with Flocor. The methane yield (1 CH4/g COD removed) was close to the theoretical yield and COD removal was around $60 \%$. An activated sludge fluidized reactor containing olive husk as a packing material was used to treat the anaerobic filter effluent. Husks were maintained in fluidized state by the aeration. This step induces COD removal at $45 \%$ and sludge (up to $2 \mathrm{~g} / \mathrm{dm}^{3}$ ). The entire process allowed a global COD reduction up to $90 \%$; however, the black colour due to polyphenolic compounds with high molecular weight persisted (Paraskeva \& Diamadopoulos, 2006).

\subsection{Enzymatic treatment}

The enzymes produced by white rot fungi were examined for bioremediation of OMW. OMW induced manganese peroxidase and laccase production in Phanerochaete flavido-alba (Anastasiou et al., 2011). Immobilized laccase from $L$. edodes was efficient in reduction of total phenols. However, the decolourizing effect was substantially lower (approximately 20\%) than reported for lignin peroxidise (D'Annibale, Stazi, Vinciguerra, \& Sermanni, 2000). Another study with $P$. chrysosporium demonstrated that lignin peroxidase was much more effective at breaking down polyphenolics by (produced $70 \%$ decolourization of the OMW) in comparison with manganese peroxidise (Sayadi \& Ellouz, 1995).

\subsection{Bioreactors used for direct OMW treatment}

Bioreactor technology enables the removal of organic pollutants (measured as COD) from OMW and is based on either aerobic or anaerobic bioreactor configurations. Aerobic bioreactor configurations are energy intensive, require high nutrient inputs to support treatment, are complex to maintain and operate, produce large quantities of waste biomass and have high capital construction costs. These are particularly significant drawbacks for treatment of relatively small-scale OMW streams. They are comprised of activated sludge and sequencing batch reactors. Also, various anaerobic bioreactor types have been tested for the treatment of OMW. There are several potential advantages with this approach including the production of a useable biogas fuel, low waste biomass generation and the generation of an excellent soil conditioner and fertilizer.

A number of basic bioreactor designs have been evaluated, including suspended biomass systems (e.g., continuously stirred tank reactors (CSTR) and retained biomass systems), the upflow anaerobic sludge blanket (UASB), the anaerobic baffled reactor (ABR), upflow and downflow anaerobic filters and the fluidized bed. The development of granular activated carbonbased bioreactor systems has also been reported (McNamara et al., 2008). Concentrated ammonia is often added to the OMW in order to overcome the poor availability of nitrogen in OMW and to stabilize bioreactor $\mathrm{pH}$. A number of authors have also successfully anaerobically co-digested the OMW with pig manures and dairy effluents, an approach which is potentially attractive as low cost nutrients are provided for digestion, inhibitory compounds present in the OMW are diluted and the digester can be operated on a year-round basis (Bouallagui, Touhami, Cheikh, \& Hamdi, 2005).

Bertin, Colao, Ruzzi, Marchetti, and Fava (2006) developed a biological post-treatment, consisting of an aerobic biological "Manville" silica bead-packed bed aerobic reactor and tested it for its ability to complete COD removal from the anaerobic digestion effluents. It was characterized biologically using molecular tools. The aerobic post-treatment was assessed through a two month-continuous feeding period with the digested effluent giving 50.42 and $2.04 \mathrm{~g} / \mathrm{L} /$ day of COD and phenol loading rates, respectively. The researchers found that it was a stable process and it was able to remove 24 and $39 \%$ of such organic loads, respectively and to account for $1 / 4$ of the overall decontamination efficiency displayed by the anaerobic-aerobic integrated system when fed with modified OMW at 31.74 and $1.70 \mathrm{~g} / \mathrm{L} /$ day of COD and phenol loading rates, respectively.

In a further study, a GAC-packed anaerobic reactor was coupled with an upflow silica bead packed bed aerobic biofilm reactor (Paraskeva \& 
Olive Mill Wastewater Treatment and Polyphenols $\mid 94$

Diamadopoulos, 2006). According to results of this study, COD removal in the anaerobic reactor was $45 \%$ and phenol removal $60 \%$. Aerobic posttreatment contributed to a further $23 \%$ COD reduction and $21 \%$ phenol reduction, resulting in final COD and phenol reductions of 59 and $76 \%$ respectively.

In another study, the general objective was to evaluate the anaerobic digestion of total raw OMW in a two-stage pilot-plant with reactors connected in series (Dalis, Anagnostidis, Lopez, Letsiou, \& Hartmann, 1996). However, the researchers' main purpose was to evaluate the performance of an up-flow-type reactor working in series with a fixed-bed-type reactor, which was used as a complementary treatment. Two different types of anaerobic digesters were used: an up-flow type and a fixed-bed type. The pilotplant system operated in the mesophilic range $\left(35 \pm 1^{\circ} \mathrm{C}\right)$ over approximately 390 days, and with organic loading levels that ranged between 2.8 and $12.7 \mathrm{~g} \mathrm{COD/l.day.} \mathrm{To} \mathrm{adjust} \mathrm{the} \mathrm{C} / \mathrm{N}$ ratio to the optimum value, concentrated aqueous ammonia was added to the total raw wastewater. This also achieved stabilisation of the $\mathrm{pH}$ values in the digesters within a range about neutrality. Seven sequential experiments were carried out. In the first stage (up-flow digester) optimum values of specific biogas production rate stabilised at a value of 2.1 litres/litre digester.day with a very satisfactory COD reduction of $83 \%$ (with a volumetric load of $11 \mathrm{~g} \mathrm{COD/l.day).} \mathrm{For} \mathrm{the} \mathrm{second}$ stage (fixed-bed digester), the biogas production rate stabilised at a value of 0.22 litres/litre digester.day with a COD reduction of $8 \%$ (with a volumetric load of $0.19 \mathrm{~g} \mathrm{COD} /$ l.d). According to the results for total raw wastewater, the performance of the applied system is amongst the best for biogas production, COD reduction and loading rate reported so far, especially for the up-flow digester. During the anaerobic digestion process, phenols were greatly reduced in both digesters, with a concentration reduction which reached $75 \%$ in the up-flow digester; with the use of the second stage (fixed-bed reactor) a further reduction of $45 \%$ was obtained.

\subsection{Oxidation and advanced oxidation processes}

Chemical oxidation using ozone, hydrogen peroxide, wet oxidation, or advanced oxidation processes (AOP) based on the generation of hydroxyl radicals (i.e., Fenton's reagent, photocatalysis, a combination of ozone with hydrogen peroxide or UV radiation) completely destroy the organic content of OMW, although they involve high operating costs and sophisticated technologies requiring qualified personnel (Panizza \& Cerisola, 2006).

Ozone and hydrogen peroxide systems are preferred because of their high oxidizing potential and the possibility of operating under atmospheric pressure and ambient temperatures without problematic decomposition products of the oxidizing agent. In order to increase oxidation rates, advanced oxidation processes (AOPs) have evolved. They constitute a suitable treatment method for industrial effluents relying upon the intermediation of chemical initiators (i.e. free radicals) and energy (i.e. heat) to destroy the target pollutants. AOPs may suitable either for the complete mineralization of all pollutants to carbon dioxide, water and mineral salts or for the selective removal of the more bioresistant pollutants and their conversion to biodegradable intermediates (Tsagaraki et al., 2007; Mantzavinos \& Kalogerakis, 2005).

The main principle of AOPs is to activate some functional groups by introducing light energy to the chemical compounds in form of radiation. Some functional groups of the reaction molecules absorbed this energy to reach an excited state before breaking the bonds leading to decomposition of the compounds. According to previous studies, several organic pollutants can be decomposed partially or totally into other less toxic and more degradable substances by oxidation based on UV light or other processes. Generally, only a small fraction of the radiant energy is absorbed by the organic molecules, causing decomposition of small percentage of the pollutant molecules. Some additives are used, such as $\mathrm{H}_{2} \mathrm{O}_{2}, \mathrm{O}_{3}$, or photo catalysis $\left(\mathrm{TiO}_{2}\right)$ to increase the rate of the decomposition process. Ozone is a powerful oxidizing agent and ozonation can be seen as a part 
of AOPs that could be used in great number of reactions with organic and inorganic compounds given that hydroxyl radical results from the decomposition of ozone. It is catalyzed by hydroxide ion or initiated by the presence of traces of other substances (Lafi et al., 2009).

An electrochemical method using Ti/Pt as the anode and stainless steel 304 as the cathode was studied (Israilides, Vlyssides, Mourafeti, \& Karvouni, 1997). In this study, experiments were run in a batch, laboratory-scale, and pilot-plant. Sodium chloride $4 \%(\mathrm{w} / \mathrm{v})$ as an electrolyte was added to the wastewater and the mixture was passed through an electrolytic cell. As a result of the strong oxidizing potential of the chemicals produced, the organic pollutants were wet oxidized to carbon dioxide and water. The researchers found that after 1 and $10 \mathrm{~h}$ of electrolysis at $0.26 \mathrm{~A} \mathrm{~cm}^{-2}$, the COD was reduced by 41 and $93 \%$, the total organic compound (TOC) was reduced by 20 and $80.4 \%$, the volatile suspended solids (VSS) were reduced by 1 and $98.7 \%$ and the total phenolic compounds were reduced 50 and $99.4 \%$, in each case with respect to the time. The mean anode efficiency was 1960 $\mathrm{g} \mathrm{h}^{-1} \mathrm{~A}^{-1} \mathrm{~m}^{-2}$ and $340 \mathrm{~g} \mathrm{~h}^{-1} \mathrm{~A}^{-1} \mathrm{~m}^{-2}$, respectively. Additionally, the mean energy consumption was $1,273 \mathrm{kWh}$ per $\mathrm{kg}$ of COD removed and $12.3 \mathrm{kWh}$ per $\mathrm{kg}$ of COD removed for 1 and 10 $\mathrm{h}$, respectively. These results show that this electrolytic method of total oxidation of OMW is not feasible. However, it could be used as an oxidation pre-treatment stage for detoxification of the wastewater. In recent years, AOPs have been extensively studied concerning their efficiency to treat OMW. When photo-Fenton with solar irradiation was used as AOP, $74 \%$ COD and $87 \%$ total phenols removal after $19 \mathrm{~h}$ with $5 \mathrm{mM} \mathrm{Fe} 2+$ and $20 \mathrm{~g} / \mathrm{l} \mathrm{H}_{2} \mathrm{O}_{2}$ achieved. With flocculation as pretreatment, COD and phenols removal increased to $89 \%$ and $100 \%$ respectively. It was commented that solar photocatalysis over $\mathrm{TiO}_{2}$ was less effective than photo-Fenton (initial $\mathrm{COD}=81 \mathrm{~g} / \mathrm{l}$ ). Electrolysis over $\mathrm{Ti} / \mathrm{Ta} / \mathrm{Pt} / \mathrm{Ir}$ anode with $\mathrm{NaCl}$ as the electrolyte procured $71 \%$ COD removal after $8 \mathrm{~h}$, complete odor, color and suspended solids removal (initial $\mathrm{COD}=45$ $60 \mathrm{~g} / \mathrm{l})$. With using Fenton followed by coagulation achieved approximately $65 \%$ COD, $30 \%$ BODu (ultimate BOD) and 100\% total phenols removal after $2 \mathrm{~h}$ with $2 \mathrm{~g} / \mathrm{l} \mathrm{FeSO}_{4} 7 \mathrm{H}_{2} \mathrm{O}$ and 5 $\mathrm{ml} / \mathrm{l} \mathrm{H} 2 \mathrm{O} 2$ dosage at $20^{\circ} \mathrm{C}$ (initial $\mathrm{COD}=80,3$ $\mathrm{g} / \mathrm{l}$ ). If just Fenton applied for OMW treatment after OME was diluted nearly 10 times prior to oxidation, 85-90\% COD removal after 3-4 h with $10 \mathrm{mM} \mathrm{Fe} 2+$ and $1 \mathrm{M} \mathrm{H}_{2} \mathrm{O}_{2}$ at $50^{\circ} \mathrm{C}$ could be achieved (initial $\mathrm{COD}=14,7 \mathrm{~g} / \mathrm{l}$ ). In this study, it was concluded that BODu/COD ratio increased or decreased following oxidation depending on the operating conditions. Supercritical wet air oxidation procured $79 \%$ COD, $79 \%$ TOC and $98 \%$ total phenols removal after $18 \mathrm{~s}$ at $500^{\circ} \mathrm{C}$ and $25 \mathrm{Mpa}$ (initial $\mathrm{COD}=3,3 \mathrm{~g} / \mathrm{l}$ ). Addition of $0,2 \mathrm{M} \mathrm{H}_{2} \mathrm{O}_{2}$ improved removal rates in this process. For this process, OME was diluted nearly 50 times prior to oxidation. In a study, subcritical wet air oxidation with or without $\mathrm{CuO} / \mathrm{C}$ or $\mathrm{Pt} / \mathrm{Al}_{2} \mathrm{O}_{3}$ catalysts and $\mathrm{H}_{2} \mathrm{O}_{2}$ was applied and approximately 50\% COD removal after $6 \mathrm{~h}$ at $180^{\circ} \mathrm{C}$ and $7 \mathrm{MPa}$ with either catalyst and $30 \%$ without catalyst were observed. Addition of $0,1 \mathrm{M} \mathrm{H}_{2} \mathrm{O}_{2}$ improved removal by $15 \%$ (initial $\mathrm{COD}=34 \mathrm{~g} / \mathrm{l}$ ). BODu/COD increased following oxidation with $\mathrm{H} 2 \mathrm{O} 2$ but remained unchanged following catalytic oxidation. Subcritical wet air oxidation coupled with Fenton was answer for $77 \%$ COD, $69 \%$ TOC and complete color removal after $1 \mathrm{~h}$ at $200^{\circ} \mathrm{C}$ (initial $\mathrm{COD}=50 \mathrm{~g} / \mathrm{l}$ ). It is commented that residual COD was aerobically degradable by a mixed culture of bacteria and yeasts. Ozonation process procured $22 \%$ COD removal after $8 \mathrm{~h}$, complete total phenols removal after $2 \mathrm{~h}$ (initial $\mathrm{COD}=34 \mathrm{~g} / \mathrm{l}$ ). Electrolysis over $\mathrm{Ti} / \mathrm{Pt}$ anode with $\mathrm{NaCl}$ as the electrolyte provided that $93 \%$ COD, $80 \%$ TOC, $99,5 \%$ total phenols and $99 \%$ suspended solids removal after $10 \mathrm{~h}$ (initial COD=178 g/l) (Mantzavinos \& Kalogerakis, 2005).

Recently, the development of new electrode materials and more compact reactors, has proven that electrochemical oxidation is a promising and attractive technique for the effective oxidation of wastewater containing non-biodegradable organic compounds. In the particular case of OMW, which has good conductivity and contains chloride ions, electrochemical methods have been reported to be very effective because the organic pollutants are oxidised either by direct oxidation at the electrodesolution interphase or by indirect oxidation in the bulk of the solution by the 
Olive Mill Wastewater Treatment and Polyphenols $\mid 96$

electrogeneration of active chlorine (Panizza \& Cerisola, 2006).

\subsection{Membrane Processes}

Membrane processes have also been tested for use in treatment of OMW because they are effective for separation of oil-water mixtures without adding solvents and could recover some valuable components to compensate for the high capital and operating costs of waste detoxification. Ultrafiltration is widely considered as a promising membrane process, since it is suitable for separation of oilwater mixtures without adding solvents while microfiltration and reverse osmosis also have been tested. Nevertheless, literature data concerning the use of membrane processes for OMW treatment are limited and they are extensively protected by strict confidentiality barriers or patents (Tsagaraki \& Lazarides, 2012; Tsagaraki et al., 2007).

The basic problem is that severe fouling of the membrane occurs very easily, strongly reducing the membrane efficiency due to gelling substances contained in OMW. Unless pretreatment is applied, recovery of membrane permeability even with regular cleaning is not possible. Thus, membrane performance is severely degraded and its lifetime is limited to one working cycle. The other negative properties of membrane processes that are the capital costs of this operation are extremely high and it is a complicated procedure that needs qualified personnel. Also, only a limited concentration factor is achieved and dissolved components such as those contributing to COD are only partially removed. Both retentate and permeate still have high COD concentrations and have to be further processed prior to disposal.

For all the reasons mentioned above, membrane processes are not suitable for the treatment of strong OMW which makes their use just for detoxification purposes economically unprofitable. They can be used as pre-treatment steps in processes that aim at the recovery of polyphenols and flavouring agents from OMW that are valuable, expensive components of OMW. Passing through the membrane, the waste becomes concentrated with these substances making their subsequent extraction easier and more economical while the high costs of the membranes are compensated by the high added value of the product. Since the retentate has a poor polyphenolic and a high oil content, it can be used as fertilizer or animal feed after appropriate treatment (Tsagaraki et al., 2007).

\section{Polyphenols from OMW}

Olives contain a variety of bioactive components. Some of them, according to their partition coefficients, end up in the water phase. One group of these are the biophenols, which have attracted increasing attention during the past few years due to their natural abundance and biological activities and are potential targets for the pharmaceutical and food industries. The phenolic compounds in olive fruits are distributed between the olive oil, the solid phase pomace or the aqueousphase wastewater, with only $1-2 \%$ partitioning into the latter. The OMW are hence a major potential source of these phenolics, particularly in consideration that annual production exceeds 7 million tonnes. The phenolic content of the OMW is reported to fluctuate between $1.0 \%$ and $1.8 \%$ depending on processing effects and varietal factors (Balasundram, Sundram, \& Samman, 2006). They can range from 1500 to $4000 \mathrm{mgl}^{-1}$ in wastewaters coming from oil mills in Italy, which can be used for the production of antioxidants (Mulinacci et al., 2001). The major phenolic components are oleuropein, hydroxytyrosol, caffeic acid and tyrosol. Numerous scientific articles prove the antimicrobial, antioxidant, antihypertensive, cardioprotective and anticarcenogenic activities of these compounds, which might be used in food, cosmetic and pharmaceutical industries ((Erbas, Gul, \& Sekerci, 2008; Gök, Kayacier, \& Telli, 2006; Coşkun, 2005). Catechol, 4-methylcatechol, hydroxytyrosol, tyrosol were characterized and isolated like the main polyphenols from olive oil mill waste waters.

Synthetic antioxidants (butylated hydroxytoluene (BHT), butylated hydroxyanisole (BHA) and tert-butylhydroquinone (TBHQ), etc.) have been used substantially as antioxidants in foods but concerns over the safety of use has led to- 
wards interest in natural antioxidants. These kind of synthetic antioxidants are substituted phenolic compounds and subsequently much of the research on natural antioxidants has also focused on phenolic compounds, particularly the hydroxycinnamic acids and flavonoids. The antioxidant activities of phenolic compounds extracted from different sources have been studied in several foods and food model systems. Antioxidants are major ingredients that protect the quality of foods by retarding oxidation. Synthetic antioxidants are sometimes used in the edible oil industry because they are inexpensive and effective. However, increased popularity of natural food additives might prompt more food manufacturers to replace synthetic antioxidants with ingredients containing natural antioxidative compounds. Hence, research about natural ingredients has gained momentum as they are usually considered to pose no health risk to consumers.

OMW could be a natural source of such useful substances. Substantially, some of the polar phenolic compounds present in extra virgin olive oil, particularly oleuropein and hydroxytyrosol, have potent scavenging action on superoxide radicals. Since the concentration of these antioxidants in OMW is 100- to 500-fold higher than that in olive oil, their recovery from OMW might be addressed with high priority. A relatively, simple, low cost, continuous extraction technique is proposed in a study by Fki, Allouche, and Sayadi (2005) in order to recover these kinds of high-value products. To extract the phenolic compounds present in OMW, optimal operational conditions were developed using a continuous counter-current extraction unit. HPLC analysis indicated a predominant presence of hydroxytyrosol $(1.43 \mathrm{~g} / \mathrm{l})$.

The effective recovery of low-molecular-mass phenolics, apart from the intrinsic economic validity, could also be beneficial for the ensuring the reduction in OMW phenolic content for further downstream applications or/and treatments. Most published research has dealt with hydroxytyrosol as the most interesting orthodiphenol which occurs in olives and derivatives, due to its antibacterial, antioxidative and beneficial effects on human health (Fki et al., 2005).

Related assays to screen some of the phenolic compounds in OMW for antioxidant properties that might be exploited as food antioxidants have been applied (Fki et al., 2005). The most active components isolated from OMW are hydroxytyrosol and 3,4-dihydroxyphenylacetic acid. They indicated a strong inhibition of linoleic acid in aqueous media and 1,1-diphenyl-2-picrylhydrazyl $(\mathrm{DPPH})$ radical scavenging activity. The addition of these components at $200 \mathrm{ppm}$ to refined oils indicated a significant retardation in the oxidation rate comparable and even superior to that of BHT. These results also suggest that the antioxidant activity of OMW extract might be a synergistic effect of 3,4-dihydroxyphenylacetic, hydroxytyrosol and other o-diphenols.

In conclusion, low-cost natural polyphenolic extracts might be produced from commercially available OMW for use as alternatives to BHT and BHA. Furthermore, the commercially available compound 3,4-dihydroxyphenyl acetic acid, which has the highest antioxidant power and the OMW-derived hydroxytyrosol, might potentially be used as alternative natural antioxidants to stabilize edible oils, while at the same time appeasing a major consumer concern over the use of synthetic antioxidants in food products.

\section{Conclusions}

OMW treatment is a complex problem which has not been satisfactorily resolved mainly due to socioeconomic and, to a lesser extent, technological reasons. Many solutions have been offered for the valorisation of olive mill wastes but many factors should be considered when selecting the best method, for instance, total waste amount, investment required to perform the treatment, available land, agronomic and industrial environment, most important needs and local laws. There is no unique solution; the solution will depend on the specific needs of the local area. The majority of olive oil producer countries in the Mediterranean area are exposed to desertification processes, so in this way the application of organic matter to the soil would be beneficial to control the erosion processes and improve soil fertility. In organic agriculture, the use of these by-products might provide an important nutrient source, closing the cycle of residue resources. Hence, the use of OMW as fertilisers or soil con- 
Olive Mill Wastewater Treatment and Polyphenols $\mid 98$

ditioners could play a fundamental role in the maintenance of the olive tree ecosystem and in sustainable agriculture. OMW are rich in antioxidant compounds which might be recovered from the matrix and employed both in preservative chemistry and, following appropriate trials to evaluate their efficacy and safety, as prophylactic agents in the prevention of certain free radical-induced human diseases.

\section{References}

Adhoum, N., \& Monser, L. (2004, October). Decolourization and removal of phenolic compounds from olive mill wastewater by electrocoagulation. Chemical Engineering and Processing, 43(10), 1281-1287. doi:10. 1016/j.cep.2003.12.001

Aktas, E. S., Imre, S., \& Ersoy, L. (2001, June). Characterization and lime treatment of olive mill wastewater. Water Research, 35(9), 2336-2340. doi:10.1016/ S0043-1354(00)00490-5

Anastasiou, C. C., Christou, P., Michael, A., Nicolaides, D., \& Lambrou, T. P. (2011). Approaches to olive mill wastewater treatment and disposal in cyprus. Environmental Research Journal, 5, 49-58. doi:10 . 3923/erj.2011.49.58

Azbar, N., Bayram, A., Filibeli, A., Muezzinoglu, A., Sengul, F., \& Ozer, A. (2004). A review of waste management options in olive oil production. Critical Reviews In Environmental Science and Technology, 34(3), 209-247. doi:10.1080/10643380490279932

Balasundram, N., Sundram, K., \& Samman, S. (2006). Phenolic compounds in plants and agri-industrial by-products: antioxidant activity, occurrence, and potential uses. Food Chemistry, 99(1), 191-203. doi:10.1016/j. foodchem.2005.07.042

Bertin, L., Colao, M. C., Ruzzi, M., Marchetti, L., \& Fava, F. (2006, April). Performances and microbial features of an aerobic packed-bed biofilm reactor developed to post-treat an olive mill effluent from an anaerobic gac reactor. Microbial Cell Factories, 5, 16. doi:10.1186/1475-2859-5-16
Bouallagui, H., Touhami, Y., Cheikh, R. B., \& Hamdi, M. (2005, March). Bioreactor performance in anaerobic digestion of fruit and vegetable wastes. Process Biochemistry, 40(3-4), 989-995. doi:10.1016/j . procbio.2004.03.007

Coşkun, T. (2005). Fonksiyonel besinlerin saglgmz uzerine etkileri. Çocuk Sağlğ ve Hastalklar Dergisi, 48, 69-84.

Dalis, D., Anagnostidis, K., Lopez, A., Letsiou, I., \& Hartmann, L. (1996, September). Anaerobic digestion of total raw oliveoil wastewater in a two-stage pilot-plant (up-flow and fixed-bed bioreactors). Bioresource Technology, 57(3), 237-243. doi:10. 1016/S0960-8524(96)00051-X

D'Annibale, A., Stazi, S. R., Vinciguerra, V., \& Sermanni, G. G. (2000, February). Oxirane-immobilized lentinula edodes laccase: stability and phenolics removal efficiency in olive mill wastewater. Journal of Biotechnology, 77(2-3), 265-273. doi:10. 1016/S0168-1656(99)00224-2

Erbas, M., Gul, S., \& Sekerci, H. (2008). Fonksiyonel gida bileseni olarak diyetsel antioksidanlar. In Turkiye 10. Gida Kongresi, Erzurum.

Fki, I., Allouche, N., \& Sayadi, S. (2005, November). The use of polyphenolic extract, purified hydroxytyrosol and 3,4dihydroxyphenyl acetic acid from olive mill wastewater for the stabilization of refined oils: a potential alternative to synthetic antioxidants. Food Chemistry, 93(2), 197204. doi:10.1016/j.foodchem.2004.09.014

Gök, V., Kayacier, A., \& Telli, R. (2006). Hayvansal ve mikrobiyal kaynakl doğal antioksidanlar. Gda Teknolojileri Elektronik Dergisi, 1(2), 35-40. Retrieved from http:// www . teknolojikarastirmalar.com/pdf/tr / 02_010206_4_gok_tr.pdf

Hachicha, R., Hachicha, S., Trabelsi, I., Woodward, S., \& Mechichi, T. (2009a, June). Evolution of the fatty fraction during cocomposting of olive oil industry wastes with animal manure: maturity assessment of the end product. Chemosphere, 75(10), 13821386. doi:10.1016/j. chemosphere.2009.02. 064 
Hachicha, S., Sellami, F., Cegarra, J., Hachicha, R., Drira, N., Medhioub, K., \& Ammar, E. (2009b, February). Biological activity during co-composting of sludge issued from the omw evaporation ponds with poultry manure-physico-chemical characterization of the processed organic matter. Journal of Hazardous Materials, 162(1), 402409. doi:10.1016/j.jhazmat.2008.05.053

Hachicha, S., Cegarra, J., Sellami, F., Hachicha, R., Drira, N., Medhioub, K., \& Ammar, E. (2009c, January). Elimination of polyphenols toxicity from olive mill wastewater sludge by its co-composting with sesame bark. Journal of Hazardous Materials, 161(2-3), 1131-1139. doi:10 . 1016 / j . jhazmat.2008.04.066

Hamdi, M., Garcia, J. L., \& Ellouz, R. (1992, October). Integrated biological process for olive mill waste-water treatment. Bioprocess Engineering, 8(1-2), 79-84. doi:10 . $1007 /$ BF00369268

Hanafi, F., Assobhei, O., \& Mountadar, M. (2010, February). Detoxification and discoloration of moroccan olive mill wastewater by electrocoagulation. Journal of Hazardous Materials, 174(1-3), 807-812. doi:10.1016/j.jhazmat.2009.09.124

Inan, H., Dimoglo, A., Simsek, H., \& Karpuzcu, A. (2004, April). Olive oil mill wastewater treatment by means of electro-coagulation. Separation and Purification Technology, 36(1), 23-31. doi:10.1016/s1383-5866(03) 00148-5

Israilides, C. J., Vlyssides, A. G., Mourafeti, V. N., \& Karvouni, G. (1997, August). Olive oil wastewater treatment with the use of an electrolysis system. Bioresource Technology, 61 (2), 163-170. doi:10.1016/S09608524(97)00023-0

Lafi, W. K., Shannak, B., Al-Shannag, M., AlAnber, Z., \& Al-Hasan, M. (2009, December). Treatment of olive mill wastewater by combined advanced oxidation and biodegradation. Separation and Purification Technology, 70(2), 141-146. doi:10 . 1016/j.seppur.2009.09.008

Mantzavinos, D., \& Kalogerakis, N. (2005, February). Treatment of olive mill effluents part i. organic matter degradation by chemical and biological processes an overview. Environment International, 31 (2), 289-295. doi:10.1016/j.envint.2004. 10.005

McNamara, C. J., Anastasiou, C. C., O'Flaherty, V., \& Mitchell, R. (2008, March). Bioremediation of olive mill wastewater. International Biodeterioration $\&$ Biodegradation, 61 (2), 127-134. doi:10.1016/j.ibiod.2007. 11.003

Morillo, J. A., Antizar-Ladislao, B., MonteolivaSanchez, M., Ramos-Cormenzana, A., \& Russell, N. J. (2009, February). Bioremediation and biovalorisation of olive-mill wastes. Applied Microbiology and Biotechnology, 82(1), 25-39. doi:10.1007/s00253008-1801-y

Mulinacci, N., Romani, A., Galardi, C., Pinelli, P., Giaccherini, C., \& Vincieri, F. F. (2001, August). Polyphenolic content in olive oil waste waters and related olive samples. Journal of Agricultural and Food Chemistry, 49(8), 3509-3514. doi:10 . 1021/ jf000972q

Panizza, M., \& Cerisola, G. (2006, March). Olive mill wastewater treatment by anodic oxidation with parallel plate electrodes. Water Research, 40(6), 1179-1184. doi:10.1016/j. watres.2006.01.020

Paraskeva, P., \& Diamadopoulos, E. (2006, September). Technologies for olive mill wastewater (omw) treatment: a review. Journal of Chemical Technology and Biotechnology, 81(9), 1475-1485. doi:10.1002/jctb.1553

Roig, A., Cayuela, M. L., \& Sanchez-Monedero, M. A. (2006). An overview on olive mill wastes and their valorisation methods. Waste Management, 26(9), 960-969. doi:10.1016/j.wasman.2005.07.024

Sayadi, S., \& Ellouz, R. (1995). Roles of lignin peroxidase and manganese peroxidase from phanerochaete chrysosporium in the decolorization of olive mill wastewaters. Applied and Environmental Microbiology, 61(3), 1098-1103. Retrieved from http:// aem. asm.org/content/61/3/1098.full.pdf + html

Tsagaraki, E., Lazarides, H., \& Petrotos, K. (2007). Olive mill wastewater treatment. In V. Oreopoulou \& W. Russ (Eds.), Uti- 
Olive Mill Wastewater Treatment and Polyphenols $\mid 100$

lization of by-products and treatment of waste in the food industry. Springer Science+Business Media.

Tsagaraki, E., \& Lazarides, H. (2012). Fouling analysis and performance of tubular ultrafiltration on pretreated olive mill waste water. Food and Bioprocess Technology, 5, 584-592. 10.1007/s11947-010-0326-4. Retrieved from 10.1007/s11947-010-0326-4

Turano, E., Curcio, S., De Paola, M. G., Calabro, V., \& Iorio, G. (2002). An integrated centrifugation-ultrafiltration system in the treatment of olive mill wastewater. Journal of Membrane Science, 209(2), 519-531. doi:10.1016/S0376-7388(02)00369-1

Yesilada, O., Sik, S., \& Sam, M. (1999). Treatment of olive oil mill wastewater with fungi. Turkish Journal of Biology, 23(2), 231-240. Retrieved from http://journals.tubitak. gov.tr/biology/issues/biy-99-23-2/biy-232-11-97058.pdf

Zenjari, B., El Hajjouji, H., Ait-Baddi, G., Bailly, J. . R., Revel, J. . C., Nejmeddine, A., \& Hafidi, M. (2006, December). Eliminating toxic compounds by composting olive mill wastewater-straw mixtures. Journal of Hazardous Materials, 138(3), 433-437. doi:10.1016/j.jhazmat.2006.05.071 